\title{
ASPECTOS NORMATIVOS BRASILEIROS EM CT\&I DA VACINA BNT162 PARA COVID-19, EM DESENVOLVIMENTO PELA PFIZER, BIONTECH E FOSUN PHARMACEUTICAL
}

\author{
Marina da Costa Miranda ${ }^{1}$ \\ Luciana Tudisco de Oliveira ${ }^{2}$
}

\section{Resumo}

O presente artigo discute as questões relacionadas aos aspectos normativos brasileiros em CT\&I da vacina BTN162 desenvolvida pela Pfizer, BioNTech e Fosun Pharmaceutical, para o coronavírus SARS- CoV-2. O objetivo principal do estudo é compreender a legislação e atos normativos brasileiros que se aplicam à autorização para realização de testes em solo nacional, de vacinas em desenvolvimento, bem como examinar a importância do investimento de um país em CT\&I.

Para tanto, a pesquisa se baseia no método exploratório-descritivo, aliado a técnicas de levantamento bibliográfico e qualitativo para análise dos dados e demonstração dos resultados parciais existentes até o momento.

Palavras-chaves: vacinação, coronavírus, CT\&I, saúde, transferência tecnológica.

\section{BRAZILIAN NORMATIVE ASPECTS IN ST\&I OF THE BNT162 VACCINE FOR COVID-19, UNDER DEVELOPMENT BY PFIZER, BIONTECH AND FOSUN PHARMACEUTICAL}

\section{Abstract}

This article discusses issues related to Brazilian regulatory aspects in ST\&I of the BTN162 vaccine developed by Pfizer, BioNTech and Fosun Pharmaceutical, for the SARS-CoV-2 coronavirus. The main objective of the study is to understand the Brazilian legislation and normative acts that apply to the authorization to carry out tests on national ground, of vaccines under development, as well as to examine the importance of a country's investment in ST\&I.

For this, the research is based on the exploratory-descriptive method, combined with techniques of bibliographic and qualitative survey for data analysis and demonstration of partial results existing to date.

Keywords: vaccination, coronavirus, ST\&I, health, technology transfer.

\section{Introdução}

\footnotetext{
${ }^{1}$ Mestranda em Direito Político e Econômico na Universidade Presbiteriana Mackenzie. Graduada em Direito. Especialista em Direito do Trabalho e Processual do Trabalho pela PUC-Campinas. Professora AnhangueraLeme. Advogada. http://lattes.cnpq.br/9340483235794704

2 Doutorado em andamento (Direito Político e Econômico- Universidade Presbiteriana Mackenzie). Analista judiciário na Justiça Federal de Primeiro Grau da 3a Região. Linha de Pesquisa em Cidadania Modelando o Estado. http://lattes.cnpq.br/5133679555972852
} 
O presente estudo tem como ponto de partida uma abordagem histórica evolutiva acerca da vacina BNT162 para COVID-19, em desenvolvimento pela Pfizer, BioNTech e Fosun Pharmaceutical.

Tem por escopo, também, analisar a legislação e atos normativos brasileiros em vigor que se aplicam à autorização para realização de testes em solo nacional, de vacinas em desenvolvimento.

Outro ponto de análise é a importância do investimento de um país em ciência, tecnologia e inovação, o CT\&I.

Em um primeiro momento, busca-se a abordar a corrida mundial por uma vacina capaz de combater o coronavírus, responsável pela declaração da pandemia de COVID-19 em 2020 pela Organização Mundial de Saúde (OMS).

Após, passa-se à análise da conduta adotada pelo Brasil no tocante à vacina BNT162. No seio desta temática, aborda-se a como vem sendo negociada pelos governos federal e estaduais e as empresas Pfizer, BioNTech e Fosun Pharmaceutical a aquisição da referida vacina para uso e futura transferência de tecnologia.

O terceiro capítulo aborda a legislação e aos normativos relativos à autorização para realização de testes da referida vacina no Brasil.

Por fim, o último capítulo versa sobre a legislação nacional em vigor para realização de transferência de tecnologia de vacinas, bem como a forma de contratação que vem sendo adotada pelo governo federal para sua aquisição.

Trata-se de uma pesquisa exploratória-descritiva, com abordagem qualitativa para análise dos dados e demonstração dos resultados parciais existentes até o momento, acompanhada de levantamento bibliográfico.

\section{A corrida por uma vacina capaz de combater o coronavírus.}

O mundo vivencia algo nunca visto antes, uma nova pandemia assolou o globo, impactando profundamente as esferas social, política e econômica.

Tudo começou na cidade de Wuhan na China, em 31 de dezembro de 2019, o país alertou a Organização Mundial da Saúde sobre o que se pensava ser vários casos de 
pneumonia. Uma semana depois, em 07 de janeiro de 2020, as autoridades chinesas comunicam que haviam verificado um novo tipo de coronavírus, o SARS-CoV-2.

Ao todo, sete coronavírus humanos (HCoVs) já foram identificados: HCoV-229E, HCoV-OC43, HCoV-NL63, HCoV-HKU1, SARS-COV (que causa síndrome respiratória aguda grave), MERS-COV (que causa síndrome respiratória do Oriente Médio) e o, mais recente, novo coronavírus (que no início foi temporariamente nomeado 2019-nCoV e, em 11 de fevereiro de 2020, recebeu o nome de SARSCoV-2). Esse novo coronavírus é responsável por causar a doença COVID-19. (OPAS, 2020).

O COVID-19 é uma doença infeciosa, que se se destaca pela sua rápida disseminação, manifestação de forma variada nas pessoas, e em como é capaz de se adaptar nas mais diferentes regiões do mundo.

Em 11 de março de 2020, a OMS decretou o COVID-19 como pandemia. De acordo com o Ministério da Saúde, o primeiro caso no Brasil foi confirmado em São Paulo, em 26 de fevereiro de 2020, em 03 de maio o país chegava a marca de 100 mil infectados, em 8 de agosto de 2020, o país já ultrapassava as 100 mil mortes causadas pelo vírus. A data de 10 de fevereiro de 2021, já são confirmados 106.586.138 de casos confirmados ao redor do mundo, contando com 2.334.774 mortes e no Brasil 9.659.167 casos confirmados e 234.850 mortes.

Os impactos da pandemia foram nas mais diversas áreas além da saúde, como já exposto, o vírus causou grande temor na população e, devido à necessidade de isolamento social para conter a sua disseminação, a economia de todo o mundo foi profundamente abalada.

Diante disso, começa a corrida contra o tempo para o desenvolvimento de uma vacina capaz de proteger a população.

Há por volta de 200 candidatas sendo desenvolvidas em busca de uma solução para o enfretamento à pandemia. No Brasil, quatro vacinas testadas vêm ganhando grande destaque devido aos seus resultados satisfatórios: vacina de Oxford, criada e desenvolvida com a farmacêutica Astrazeneca; a empresa chinesa Sinovac com o Instituto Butantã e a vacina CoronaVac; a empresa europeia Janssen-Cilag com a vacina AD26.COV2.S; e a BNT162b2 vacina desenvolvida em uma parceria entre três empresas, a americana Pfizer, a alemã BioNTech e chinesa Fosun Pharmaceutical. Será nesta última vacina que o presente artigo irá se concentrar.

Entende-se ser necessário, em um primeiro momento, compreender como se deu a união das três empresas para, em seguida, se aprofundar no desenvolvimento da vacina. 
A Pfizer é uma empresa americana, fundada em 1849, em Nova York, por Charles Pfizer e Charles Erhart, dois primos e imigrantes alemães.

A empresa ingressou no Brasil em 1952, sua sede fica na cidade de São Paulo e conta com uma fábrica em Itapevi. Ao redor do mundo são 58 unidades industriais. A companhia é focada na descoberta de tratamentos inovadores, com investimentos em pesquisa e desenvolvimento (P\&D) globais de US\$ 8 bilhões. Nos estudos para a descoberta de novos medicamentos a Pfizer faz parcerias com universidades, laboratórios e empresas, (Pfizer, 2020a).

No combate ao coronavírus, juntamente com a busca pela vacina, a Pfizer Brasil e Pfizer Foundation (organização filantrópica) realizaram doações para as necessidades das comunidades mais afetadas pelo COVID-19 e para projetos que corroboram com o sistema de saúde nacional, que somam $\mathrm{R} \$ 2,5$ milhões de reais. Ao redor de todo o mundo essas doações chegaram a R\$ 40 milhões. (PFIZER, 2020b)

Em março de 2020, a BioNTech anunciou uma parceria com a Pfizer no desenvolvimento da vacina para combater o SARS-CoV-2. A BioNTech é uma empresa de imunoterapia alemã, com sede em Mainz, fundada em 2008 pelo casal turco Ugur Sahin e Oezlem Tuereci. A companhia tinha como foco desenvolver vacinas personalizadas para serem utilizadas em tratamentos de câncer. Em janeiro de 2020, ao notar a gravidade e potencialidade do novo vírus, a empresa decidiu empregar seus esforços no desenvolvimento de uma vacina capaz de combater o COVID-19.

Esta união em busca da vacina também conta com a empresa chinesa Shangai Fosun Pharmaceutical, fundada em 1992 e integrante do grupo Fosun International Limited. A empresa trabalha no fornecimento e desenvolvimento de produtos nos setores de saúde e felicidade, a companhia possui atuação global, mas se destaca pela sua atuação no Japão. Na luta contra o coronavírus a Fosun se sobressaiu com uma grande entrega de lotes de suprimentos médicos para o Japão e Coréia do Sul, incluindo máscaras, óculos, luvas e trajes médicos de proteção (FOSUN, 2020).

As empresas BioNTech e Pfizer possuem um acordo e trabalham em parceria desde 2018, na busca de vacinas baseadas em mRNA para combater a influenza, um vírus da gripe. As empresas utilizam esse mesmo material genético no desenvolvimento da vacina que objetiva prevenir infecções pelo coronavírus. 
As negociações começaram em fevereiro, quando a bioNTech, que estava desde janeiro mobilizada em encontrar uma solução para o novo vírus que assolava o mundo, ofereceu a parceria no desenvolvimento da vacina à Pfizer, que aceitou a proposta. A parceria foi anunciada em março de 2020, sendo firmado um Acordo de Colaboração e Transferência de Material.

A empresa americana se comprometeu a investir um bilhão de dólares no projeto, com o pronto pagamento de U\$ 185 milhões, em junho as empresas também receberam um investimento de cem milhões de euros do Banco Europeu de Investimentos, que deverão ser pagas em duas parcelas de 50 milhões liberadas conforme a evolução das pesquisas. (OLIVEIRA, 2020)

A BioNTech é proprietária da tecnologia de vacinas de mRNA e durante estágio de desenvolvimento a empresa fornecerá os suprimentos clínicos da vacina. Além disso, a fabricação do mRNA também será realizada em sua fábrica, que possui certificação GMP (Good Manufacturing Practices) na Europa. A Pfizer enriquece a colaboração, pois possui um alto nível de experiência em pesquisa e desenvolvimento de vacinas, uma grande rede global de fabricação e distribuição e recursos regulatórios. Trata-se de uma grande união de recursos e conhecimento.

Em 16 de março é anunciada uma colaboração estratégica com a empresa chinesa Fosun Pharmaceutical, para possibilitar a condução de testes clínicos e comercialização da vacina BNT162 na China, mediante aprovação regulatória.

As parcerias visam possibilitar desenvolvimento e o acesso global de uma vacina contra o covid-19 o mais rápido possível, tal é a missão das empresas que o projeto do desenvolvimento da vacina recebeu o nome de Project Lightspeed.

Nos estudos tradicionais para o desenvolvimento de vacinas a lógica utilizada pelos cientistas é a injeção nos pacientes de proteína dos vírus ou injetar o próprio vírus, que pode estar inativo ou atenuado, então espera-se que o organismo do paciente desenvolva uma resposta imunológica a esse "invasor". O grande diferencial da vacina BNT16b2, é a inovadora técnica adotada pela BioNTech de vacinas baseadas em mRNA, as quais transportam a instrução para tornar o corpo capaz de produzir uma proteína chamada spike, que se encontra presente no SARS-CoV-2. Uma vez que o organismo já possui essas proteínas. Caso venha reconhecer a presença do vírus, ele passará a produzir os anticorpos 
necessários para combatê-lo. Vale destacar que a vacina é aplicada em duas doses, com 21 dias de espaçamento entre elas.

As vacinas de mRNA consistem em material genético, denominado RNA mensageiro, que fornece instruções para uma célula humana produzir uma proteínaalvo, ou imunógeno, que ativa a resposta imune do corpo contra o respectivo vírus. O objetivo de uma vacina é estimular o sistema imunológico a gerar respostas de células $\mathrm{T}$ e anticorpos protetores de longa duração contra a SARS-CoV-2 e prevenir a infecção subsequente após a exposição ao vírus. As vacinas de mRNA são uma nova classe potente de vacinas em desenvolvimento com potencial para alta versatilidade e propriedades de segurança favoráveis. (BIONTECH, 2020)

A aprovação dessa vacina não é uma vantagem apenas para a luta contra o COVID19, mas no desenvolvimento de vacinas em geral, visto que seria a primeira vacina de RNA a ser aprovada no mundo.

Mas há um grande desafio na comercialização da vacina, pois ela precisa ser armazenada em uma temperatura correspondente a $-75^{\circ} \mathrm{C}$, o que traz preocupação sobre sua viabilidade logística e aplicação em regiões muito quente ou nas áreas marginalizadas, que possuem pouco acesso à energia elétrica. Contudo, em entrevista para a revista VEJA o CEO da PFIZER Brasil, Carlos Murillo, garantiu que a companhia está trabalhando não só no desenvolvimento da vacina, mas também, na de sua embalagem:

\footnotetext{
Nós não temos trabalhado apenas na tecnologia de desenvolvimento da vacina, mas também na embalagem. A companhia desenvolveu uma caixa especial que mantém a vacina na temperatura adequada por 15 dias. Após esse período, é possível trocar apenas o gelo seco dessa embalagem e o armazenamento está garantido por mais 15 dias. A embalagem permite fazer essa manobra três vezes. Ou seja, nesse pack que a Pfizer está disponibilizando, é possível armazenar as doses na temperatura adequada por até 45 dias. Além disso, sabemos que a vacina tem estabilidade de pelo menos 5 dias em condições normais de refrigeração, infraestrutura amplamente disponível no Brasil graças ao Programa Nacional de Vacinação. Então o que realmente era uma dúvida e uma preocupação forte, se tornou um ponto manejável e isso foi explicado ao governo brasileiro. (MURILLO, 2020)
}

A corrida por uma vacina eficaz contra o COVID-19, conforme assinalado, tem movimento grande parte da indústria farmacêutica. O próximo capítulo examinará, em específico, a vacina BNT162, desenvolvida pela Pfizer, BioNTech e Fosun.

\section{A vacina BNT162 no Brasil.}

A princípio, o Project Lightspeed contava com quatro formatos de vacinas. O desenvolvimento de uma vacina conta com 3 etapas. 
Em um primeiro momento é realizada a pesquisa básica e os testes não clínicos, identificando os potenciais candidatos à vacina e com a realização de testes preliminares em animais e em laboratório.

Em seguida, começam os estudos clínicos realizados em humanos, fase dividida em três etapas: na primeira fase dos testes em humanos será avaliada a segurança da vacina e as reações aceitáveis; na segunda fase, será avaliada a dose, o esquema de vacinação e a imunogenicidade das vacinas; já a terceira fase conta com os estudos realizados em grandes populações, verificando a eficácia e a segurança da vacina.

Por fim, após a verificação da eficácia segurança e qualidade da vacina, é realizado o seu registro, no caso do Brasil, este é feito pela ANVISA e tornará possível a comercialização e disponibilização no país. (ANVISA 2020).

No dia 21 de julho, por meio da Resolução-RE n. 2.556, foi publicada no Diário Oficial da União a autorização para ensaios clínicos para as vacinas BNT162 com RNA antiviral para imunização ativo contra COVID-19, formulado pela WYETH Indústria Farmacêutica LTDA. (IMPRENSA NACIONAL, 2020).

No dia 09 de novembro de 2020, Pfizer e BioNTech anunciaram que, de acordo com os dados iniciais da terceira fase dos testes, a vacina BNT162b2 mostrou ser mais de $90 \%$ eficaz na prevenção do vírus. Esses números superam em muito as expectativas e aumentam a esperança da vitória na luta contra o COVID-19, pois muitas das vacinas em uso hoje apresentam eficácia comprovada em torno de 60 a 70\%, a agência regulatória dos Estados Unidos, FDA, já havia anunciado que as vacinas, para serem liberadas, deveriam comprovar uma eficácia de $50 \%$.

\begin{abstract}
Os resultados são baseados em uma análise provisória conduzida após 94 participantes, divididos entre aqueles que receberam um placebo e aqueles que foram vacinados, contraíram Covid-19. O julgamento continuará até que ocorram 164 casos. Se os dados se mantiverem e uma houver uma leitura de segurança, que a Pfizer espera que se dê em cerca de uma semana, também parecer boa, isso pode significar que o mundo tem uma nova ferramenta vital para controlar uma pandemia que matou mais de 1,2 milhão de pessoas ao redor do mundo (LANGRETH, KRESGE e GRIFFIN, 2020) (tradução nossa)3
\end{abstract}

\footnotetext{
${ }^{3}$ No original: The findings are based on an interim analysis conducted after 94 participants, split between those who got a placebo and those who were vaccinated, contracted Covid-19. The trial will continue until 164 cases have occurred. If the data hold up and a key safety readout Pfizer expects in about a week also looks good, it could mean that the world has a vital new tool to control a pandemic that has killed more than 1.2 million people worldwide.(LANGRETH, KRESGE e GRIFFIN, 2020)
} 
Diante dos bons prognósticos da vacina vários países contrataram com as empresas para garantirem suas doses, assim que a vacina fosse aprovada.

A União Europeia, autorizou no dia 11 de novembro que a Comissão Europeia fechasse o contrato de compra de 300 milhões de doses da vacina desenvolvida pela Pfizer e BioNTech. (MANCINI, MILLER e KUCHLER, 2020)

Com os EUA, as empresas fecharam um contrato de 1,5 bilhão de dólares, para entregarem cem milhões de vacinas, começando ainda no ano de 2020. Além disso, o Japão encomendou 100 milhões de doses e o Reino Unido 40 milhões. (GRYZINSKI, 2020)

Em agosto de 2020, após várias reuniões com integrantes do governo, inclusive com os Ministérios da Saúde e da Economia, a Pfizer e a BioNTech apresentaram uma proposta formal para o Brasil, em que se ofertava incluir o país na primeira leva da vacina após sua aprovação, o que resultaria na vacinação de milhares de brasileiros entre o fim de 2020 e o início de 2021. Contudo, o governo tinha um prazo de reposta e não o fez. Ainda assim, defendendo uma distribuição equitativa das vacinas e nos benefícios de sua aplicação na maior parte possível da população mundial, após a expiração do prazo de resposta do governo, o CEO da Pfizer no Brasil, enviou uma carta ao presidente Jair Bolsonaro e ao Ministro da Saúde, reiterando a proposta. Contudo, continuaram sem uma devolutiva do governo.

\footnotetext{
Quando fazemos uma proposta, nós reservamos a quantidade de doses negociada e colocamos um prazo para resposta porque se não temos uma sinalização de interesse, o mais correto é distribuir essas unidades para outros países. A vacina vem avançando bem e a companhia assumiu o risco de começar a produção de unidades antes da aprovação regulatória. Isso permite que a companhia já tenha milhões de doses disponíveis em 2020 e mais no início do ano. Por conta desses avanços, nossa posição foi negociar acordos de compra avançada com os governos, que permitam uma distribuição mais equitativa. Uma das coisas que sabemos, pela quantidade que nós conseguimos produzir, e também as outras empresas, é que, sobretudo nesta primeira etapa, não vai ter vacina suficiente para o mundo todo. Então essas negociações de compra avançada permitem seguir de maneira mais justa. Trabalhamos com diferentes governos para entender quais seriam os primeiros a receber a vacina e alocar o quantitativo necessário nos diferentes países. É assim que a companhia já assinou acordos com os Estados Unidos, Japão, Canadá, países da comunidade Europeia, Chile, Peru, Costa Rica, entre outros. (MURILLO, 2020)
}

O entrave com o governo brasileiro se dá em torno da requisição por transferência de tecnologia. O Brasil realizou um acordo com as farmacêuticas Oxford e AstraZeneca, em que ocorrerá a transferência de tecnologia e a vacina será produzida em Manguinhos. O governo do Estado de São Paulo realizou um acordo semelhante com a empresa chinesa Sinovac, 
produtora da vacina CoronaVac. Neste caso, a produção no Brasil vem sendo realizada em parceria com o Instituto Butantã.

É comum que países em desenvolvimento, usem acordos de transferência de tecnologia como forma de se manterem competitivos no mercado. Trata-se de uma estratégia em desenvolvimento e crescimento econômico, em crescimento. A transferência de tecnologia possibilita ao país ter grandes ganhos de capacitação tecnológica. Geralmente, recebe-se a nova tecnologia e, a partir disso, o país faz adaptações, melhorias e depois realiza sua difusão.

O Brasil é conhecido por sua grande dependência internacional em termos de tecnologia, uma vez que tem baixíssimos índices de investimento em P\&D e C\&T, inclusive, o governo atual realiza cada vez mais cortes de gastos nesse sentido, enquanto deveria caminhar em direção oposta, para obter um desenvolvimento econômico e social estável. O assunto será discutido no tópico seguinte, o que se pretende agora é apenas demonstrar que não surpreende o desejo do governo pelo acordo de transferência de tecnologia.

$\mathrm{Na}$ indústria farmacêutica brasileira o ativo principal das empresas que possuem posições dominantes é de natureza comercial. Ele está corporificado em equipes de vendas numerosas; e mesmo firmas que são filiais de empresas multinacionais e possuem no exterior equipes de pesquisa produtivas e ativos tecnológicos relevantes acabam muitas vezes por pagar às empresas bem implantadas no mercado nacional brasileiro o tributo ao seu ativo comercial de importância superior. Este tributo ocorre na forma de licenciamento para produção final (quer dizer, formulação do medicamento com princípio ativo fornecido pelo licenciador) e comercialização de medicamento da carteira de produtos da empresa multinacional. (FURTADO, 2005, p.17)

Contudo, a Pfizer já se manifestou que não há possibilidade, ao menos no momento, de realizar a transferência de tecnologia com o Brasil: A Pfizer, porém, descarta assinar agora um acordo de transferência de tecnologia
que permita ao Brasil fabricar sua vacina aqui. O imunizante criado pela
farmacêutica usa uma tecnologia nova, à base de RNA, material genético do vírus,
para a qual nenhuma planta brasileira é adequada. A rigor, diz a empresa, nenhuma
planta no mundo comporta ainda os requisitos.
- Numa etapa inicial, a posição da companhia é que a forma mais eficiente e mais
rápida de assegurar o maior quantitativo possível de vacina é concentrar a produção
em três plantas nos EUA e duas na Alemanha - afirma Murillo. - Elas são as mais
avançadas, que permitem adequação mais rápida desta nova plataforma de
tecnologia. (GARCIA,2020)

Quanto a políticas de preços, a Pfizer não divulgou o valor da vacina para o Brasil, por ainda estarem em fase de negociação, mas garantiu que foi definido preços diferentes para os 3 grupos de países: desenvolvidos, em desenvolvimento e subdesenvolvido. 
A companhia definiu preços diferentes para três grupos. Para países em desenvolvimento, como é o caso do Brasil, o preço é significativamente menor que o de países desenvolvidos, como Estados Unidos e países europeus. Por outro lado, o valor para os países subdesenvolvidos, como alguns países africanos, é ainda menor. Assim, os países com mais recursos acabam ajudando e subsidiando os países com menos recursos. E estes países basicamente cobrem o que seria o custo de produção da vacina. Praticamente todas as outras companhias receberam muitos milhões de dólares para desenvolver suas vacinas. No preço, isso precisa ser considerado. A tecnologia utilizada no desenvolvimento da vacina também influencia. (MURILLO, 2020)

Ainda que não se tenha a transferência de tecnologia, há muitas outras vantagens na contratação da vacina de mRNA, vez que, por se tratar de uma vacina gênica não é preciso cultivar grande quantidade de vírus para usar como matéria-prima e em seguida atenuá-lo, como no caso das tradicionais vacinas atenuadas ou inativadas, ou seja, é possível a produção em laboratório apenas da sequência genética desejada, o que faz com que a vacina seja mais barata e tenha uma produção mais rápida.

Além disso, o método também é mais seguro.

\footnotetext{
Os vírus neste estado foram manipulados para serem menos perigosos, mas ainda assim eles conseguem se reproduzir lentamente. Isso dá tempo suficiente para que o sistema imunológico de uma pessoa saudável reaja e, neste processo, aprenda a combater essa ameaça. Mas, em casos mais raros, se o paciente é imunocomprometido, ele pode perder essa corrida contra o vírus, e a pessoa fica doente.

"Com esse tipo de vacina, não tem isso, porque ela não usa um micro-organismo vivo. É completamente sintética", diz Norbert Pardi, da Universidade da Pensilvânia. (BBC,2020)
}

Isto é, o método desenvolvido pelas empresas americana e alemã é mais barato, mais seguro e muito eficaz. E claro, a grande vantagem e a necessidade mais urgente é a imunização em massa da população brasileira, o que desencadeará benefícios não só no aspecto da saúde, mas também econômico, pois o mercado poderá retomar seu funcionamento.

\section{Testes e acordos para contratação de vacinas pelo Brasil}

A pandemia de Covid-19 trouxe à tona problemas estruturais existentes em diferentes nações. Pode-se dizer que nenhuma nação estava totalmente preparada para enfrentá-la com o vigor necessário diante da situação alarmante. 
A pesquisa no campo da vacina envolve uma série de fases de custo progressivamente alto. Durante seu desenvolvimento, a pesquisa pode falhar e o alto investimento financeiro pode não obter a resposta esperada, ante um resultado incerto.

Desde a decretação da pandemia de Convid-19 pela Organização Mundial da Saúde OMS, pesquisadores do mundo inteiro têm sido pressionados a oferecer respostas rápidas e eficientes.

A partir da segunda guerra mundial a ciência tornou-se central para a estratégia política e econômica dos Estados.

No tocante ao progresso brasileiro na seara da ciência e tecnologia, em 1982 foi criada pela Sociedade Brasileira para o Progresso da Ciência, a revista Ciência Hoje, que se tornou precursora de uma série de publicações de disseminação e divulgação científica.

Dando um salto na história brasileira, a partir do século XXI, o país passou a experimentar um foco maior em investimentos nas áreas de Ciência, Tecnologia e Inovação.

\begin{abstract}
De acordo com dados do Instituto Brasileiro de Geografia e Estatística (IBGE) sobre a porcentagem de investimentos em $\mathrm{P} \& \mathrm{D}$ em relação ao Produto Interno Bruto (PIB), entre 2000 e 2017, o país oscilou entre 0,96\% (2004) e 1,34\% (2015), atingindo 1,26\%, em 2017 - último ano da série histórica. No mesmo período, segundo dados do Banco Mundial, a média mundial dos 149 países analisados pelo mesmo critério variou entre 1,94 (2007) e 2.22\%, em 2017 - último ano em que há dados disponíveis. Em 2017, a média de investimentos em P\&D dos países membros da Organização para a Cooperação e Desenvolvimento Econômico (OCDE) foi de $2,56 \%$ do PIB. Há uma tendência de alta na média mundial, enquanto estima-se que no Brasil os últimos anos foram de queda.4 (OLIVEIRA, SOUZA, 2020).
\end{abstract}

Segundo o mesmo autor:

O ano de 2016 marcou o fim e a reversão de um ciclo, que durou quatro anos ininterruptos, em que os investimentos do Brasil em pesquisa e desenvolvimento (P\&D) cresceram de forma regular e consistente no Brasil. O dispêndio nacional em P\&D naquele ano alcançou 1,27\% do Produto Interno Bruto (PIB), abaixo do 1,34\% obtido em 2015, um recorde histórico. Em valores corrigidos pela inflação em 2016, a queda foi de $9 \%$ - de $\mathrm{R} \$ 87,1$ bilhões para $\mathrm{R} \$ 79,2$ bilhões de um ano para o outro. O PIB brasileiro recuou 3,6\% em 2016, em um momento agudo de recessão. (OLIVEIRA, SOUZA, 2020).

É, sobretudo, em tempos de crise que a falta de investimentos em pesquisas científicas reflete e impacta diretamente na sociedade. Pode-se afirmar que o Brasil possui uma história de sucesso no combate a crises de saúde pública e pandemias. Embora o país tenha vivido, conforme já assinalado, períodos de maiores investimentos em ciência e

\footnotetext{
${ }^{4}$ Ebook santos e Pochmann p 42
} 
tecnologia, a CT\&I nacional deixou de ser uma prioridade, sobretudo para o governo atual, ante as declarações anti-ciência quase que diárias e os ataques às universidades.

O objeto do presente capítulo é abordar a legislação nacional em vigor sobre CT\&I, com foco na compra pública de vacinas e testagem.

Atualmente, no Brasil estão em vigor as seguintes normas legais no âmbito federal:

[i] Lei de Inovação Tecnológica (Lei Federal n. 10.973/2004), que dispõe sobre incentivos à inovação e à pesquisa científica e tecnológica no ambiente produtivo e dá outras providências, parcialmente alterada pela Lei n. 13.243/2016;

[ii] Marco Legal de Ciência, Tecnologia e Inovação (Lei Federal n. 13.243/2016), trazendo estímulos ao desenvolvimento científico, à pesquisa, à capacitação científica e tecnológica e à inovação. Referida lei representa um avanço significativo ao desburocratizar o processo de transferência de tecnologia e de investimentos em inovação, fundamental para o desenvolvimento científico no país;

[iii] Lei do Bem (Lei n. 11.196/2005), que instituiu o Regime Especial de Tributação para a Plataforma de Exportação de Serviços de Tecnologia da Informação - REPES, o Regime Especial de Aquisição de Bens de Capital para Empresas Exportadoras - RECAP e o Programa de Inclusão Digital; dispõe sobre incentivos fiscais para a inovação tecnológica;

[iv] Lei do Fundo Nacional de Desenvolvimento Científico e Tecnológico (Lei n. 11.540/2007). Referido fundo tem por objetivo financiar a inovação e o desenvolvimento científico e tecnológico com vistas em promover o desenvolvimento econômico e social do País, conforme disposto no artigo $1^{\circ}$ (PLANALTO, 2020);

[v] Emenda Constitucional 85/2015, que estimula o desenvolvimento científico, tecnológico e a inovação. Um dos principais objetivos é impulsionar a pesquisa nacional e a criação de soluções tecnológicas que aperfeiçoem a atuação do setor produtivo (SENADO, 2020); e

[vi] Decreto Federal de Inovação (Decreto federal n. 9.283, de 2018), que regulamenta a Lei de Inovação Tecnológica (Lei Federal n. 10.973/2004) e o Marco Legal de Ciência, Tecnologia e Inovação (Lei Federal n. 13.243/2016), para estabelecer medidas de incentivo à inovação e à pesquisa científica e tecnológica no ambiente produtivo, com vistas à capacitação tecnológica, ao alcance da autonomia tecnológica e ao desenvolvimento do sistema produtivo nacional e regional. 
No que diz respeito ao assunto ora em análise, importante trazer à baila a entrada em vigor da Lei 13.979, de 06 de fevereiro de 2020, alterada pela Lei 14.035 de 11 de agosto de 2020, dispondo sobre as medidas para enfrentamento da emergência de saúde pública de importância internacional decorrente do coronavírus, responsável pelo surto de 2019.

Referida lei, em seu artigo $4^{\circ}$, por exemplo, traz a autorização para dispensa de licitação para aquisição ou contratação de bens, serviços, inclusive de engenharia, e insumos destinados ao enfrentamento da emergência de saúde pública de importância internacional.

$\mathrm{O}$ artigo $4^{\circ}-\mathrm{C}$ estabelece que,

Para a aquisição ou contratação de bens, serviços, inclusive de engenharia, e insumos necessários ao enfrentamento da emergência de saúde pública de que trata esta Lei, não será exigida a elaboração de estudos preliminares quando se tratar de bens e de serviços comuns.

Ainda, o artigo $4^{\circ}$-D estabelece que "O gerenciamento de riscos da contratação somente será exigível durante a gestão do contrato. ”

No tocante à aprovação de testagem de vacinas para a Covid-19, em razão da emergência de saúde pública, a ANVISA editou atos normativos de maneira célere. Um desses atos é a Resolução da Diretoria Colegiada (RDC) 348, aprovada em 17 de março de 2020, que definiu os critérios e os procedimentos extraordinários e temporários para tratamento de petições de registro de medicamentos, produtos biológicos e produtos para diagnóstico in vitro e mudança pós-registro de medicamentos e produtos biológicos em virtude da emergência de saúde pública internacional decorrente do novo Coronavírus.

$\mathrm{O}$ ato normativo editado pela ANVISA que interessa diretamente ao presente estudo é a Nota Técnica $n^{\circ} 78 / 20$, que trouxe orientações quanto à submissão de documentação técnica para análise pela referida agência, relacionada a vacinas para a prevenção da Covid19.

Um dos desafios trazidos pela pandemia de Covid-19 é o de regulamentar a disponibilização de medicamentos para tratamento e prevenção a enfermidade de forma rápida, porém, segura. Por meio da referida Nota Técnica, a Gerência de Avaliação de Produtos Biológicos - GPBIO/GGMED busca instruir as empresas que têm interesse em registrar no Brasil vacinas para prevenção da Covid-19, dispondo sobre o procedimento de submissão de documentação técnica do produto na medida em que esta for sendo disponibilizada pelas empresas, denominado de submissão contínua.

De acordo com informação retirada do site da ANVISA, 
(...) Por meio desse procedimento de submissão, conforme os dados técnicos forem gerados, estes deverão ser apresentados à Agência, de modo que o processo regulatório seja agilizado. Dessa forma, as empresas interessadas no registro de vacinas Covid-19 não precisarão aguardar a disponibilização de todos os dados e documentos técnicos nem o preenchimento de todos os requerimentos regulatórios para então apresentá-los à Anvisa por meio da submissão do pedido de registro.

Importante ressaltar que o procedimento de submissão contínua não afeta em nada o padrão de qualidade requerido. A estratégia tem como objetivo acelerar a disponibilização à população brasileira de vacinas contra o novo coronavírus, desde que demonstradas a sua qualidade, segurança e eficácia, conforme os requerimentos técnicos e regulatórios vigentes.(ANVISA, 2020)

O procedimento estabelecido pela Nota Técnica consiste em:

[i] Primeira submissão (petição primária): a empresa interessada deverá protocolar eletronicamente o assunto 11800 - Produtos Biológicos - Avaliação de dados preliminares para COVID-19, devendo conter justificativa, status regulatório mundial, histórico de interações prévias com a Anvisa e cronograma de submissão da documentação técnica a ser avaliada.

[ii] Aditamentos específicos de qualidade, eficácia e segurança (códigos 11811 PRODUTO BIOLÓGICO - Aditamento CMC - Covid-19 e 11812 - PRODUTO BIOLÓGICO - Aditamento Eficácia e Segurança - Covid-19): sob o código 11811, a empresa interessada deverá submeter para avaliação a documentação relacionada à qualidade do produto e, sob o código 11812,deverá ser encaminhada a documentação referente aos estudos não clínicos e clínicos. A ANVISA disporá do prazo de até vinte dias após o protocolo de aditamento para analisar a documentação.

O procedimento se repete a cada nova submissão.

Quando da disponibilização do Plano de Gerenciamento de Risco ou parte dele, a empresa deve peticionar este documento pelo código referente ao assunto Plano de Gerenciamento de Risco/Plano de Minimização de Risco - Vacina COV-19.Paralelamente, a empresa deve enviar um e-mail para farmacovigilancia@anvisa.gov.br como título VACINA COVID - SUBMISSÃO CONTÍNUA, informando sobre o número do processo e o protocolo realizado. Para informações adicionais ou complementação deste documento, deverá ser seguido o mesmo procedimento, ou seja, protocolar o código de assunto mencionado e enviar e-mail para a Farmacovigilância.(ANVISA 2020)

No que diz respeito à submissão do pedido de registro, a Nota esclarece que:

Os produtos que tiverem sua análise iniciada pelo procedimento de submissão contínua poderão ter submetido seu pedido de registro formal após a conclusão do último aditamento protocolado e após avaliação pela empresa quanto à suficiência dos dados de qualidade, eficácia e segurança para o estabelecimento de uma relação de benefício-risco positiva e robusta, considerando a indicação terapêutica pleiteada e as discussões prévias com a Anvisa.(ANVISA, 2020). 


\section{Transferência de tecnologia e demais vantagens para o país com a contratação da vacina}

Os benefícios trazidos por uma vacina são notáveis e comprovados por meio de estudos científicos.

Embora cada país seja responsável pela saúde de sua população, o reflexo de tal cuidado ultrapassa as fronteiras do país, alcançando um benefício coletivo internacional, ante a circulação de pessoas.

Ações para eliminação de doenças devem envolver medidas multinacionais conjuntas.

O setor de vacinas sofreu profundas modificações ao longo do século $\mathrm{XX}$, no que diz respeito ao modelo de gestão da inovação. Tradicionalmente, com o intuito de gerar inovação e aumentar a competitividade, as empresas investiam em sua própria pesquisa e desenvolvimento, a chamada de "Inovação Fechada" (CHESBROUGH, 2003).

A disseminação do conhecimento e outros fatores tornaram esse modelo insustentável, o que levou ao surgimento da "Inovação Aberta". Aqui, ideias podem surgir dentro ou fora da empresa, de modo que o ambiente externo se torna relevante.

No cenário atual, o setor público exerce um importante papel no desenvolvimento da pesquisa básica e empresas e biotecnologia assumem um papel de grande relevância nas etapas iniciais da $\mathrm{P} \& \mathrm{D}$. No que diz respeito às etapas finais do desenvolvimento, são as indústrias e as empresas multinacionais que lideram (LOPES, 2016). Após essas etapas, as vacinas são licenciadas (aprovadas para uso) pelas autoridades regulatórias nacionais.

O modelo brasileiro de imunização em massa é uma referência mundial. Por meio do Programa Nacional de Imunização (PNI), criado em 1973, alcançou-se altos índices de cobertura vacinal em todas as camadas da população. O modelo brasileiro tem por base a produção de vacinas realizadas pelos laboratórios oficiais, destacando-se o Bio-Manguinhos e Instituto Butantan (GADELHA e AZEVEDO, 2003).

A partir da década de 1980, o Brasil tornou-se dependente dos laboratórios privados, em razão da crescente demanda por vacinas e soros, período em que houve uma crescente exigência regulatória e problemas com qualidade. A partir deste cenário, "a criação do Programa de Autossuficiência Nacional em Imunobiológicos (PASNI), em 1986, passou a ter fundamental influência na modernização do parque nacional de produção de vacinas, com 
investimentos mais significativos nas melhorias tecnológicas dos laboratórios oficiais" (PORTES, 2012).

Atualmente, o investimento público no setor de vacinas continua crescendo e o PNI é considerado um dos programas mais efetivos dentre os países em desenvolvimento.

Ao longo dos últimos anos, o governo federal tem utilizado seu poder de compra e disponibilizado o mercado nacional como objeto de troca para a realização de projetos de transferência de tecnologia no setor de vacinas (HOMMA e OLIVEIRA, 2008). Hoje, grande parte das vacinas disponíveis no PNI são oriundas de alianças estratégicas realizadas entre os laboratórios oficiais e as empresas multinacionais. Nos laboratórios públicos, os quais interessa ao presente estudo, existe um trabalho articulado para a produção de vacinas combinadas. Quando tal articulação envolve uma empresa estrangeira, são realizados acordos de transferência de tecnologia.

A transferência de tecnologia permite grandes avanços em termos de modernização tecnológica para o Brasil e, uma das vantagens, é a redução de gastos com a importação de produtos e maior aporte de recursos para investir em atividades de P\&D (PORTES, 2012).

A legislação brasileira, conforme já assinalado, prevê a possibilidade de parcerias entre o Estado e empresas privadas. Interessa ao presente estudo analisar a modalidade de parceria aplicada à área da saúde, em especial, à voltada à transferência de tecnologia de produção de vacinas.

A contratação de transferência de tecnologia de vacina para Covid-19, realizada pelo governo federal com a Fiocruz e AstraZeneca, se deu por meio de ETEC (Encomenda Tecnológica), vez que o modelo utilizado anteriormente (Parcerias para o Desenvolvimento Produtivo - PDP) apresentou diversos problemas.

A ETEC corresponde a uma compra pública voltada a encontrar solução para determinado problema por meio de desenvolvimento tecnológico. O foco são as atividades de pesquisa que envolvam risco tecnológico. A contratação é realizada por meio de esforço tecnológico desenvolvido ou em fase de desenvolvimento de uma Instituição Científica e Tecnológica (ICT).

Segundo RAUEN (2019), ETECs são tipos especiais de compras públicas diretas voltadas a situações muito específicas nas quais exista risco tecnológico.

São reguladas pelo Artigo 24, inciso XXXI da Lei no 8.666/1993, pelo artigo 20 da Lei no 10.973/2004 e pela seção V do Decreto no 9.283/2018. 
Trata-se de hipótese de dispensa de licitação, devendo ser motivada pelo administrador. Com o advento da Lei n. 13.243/2016, que alterou parcialmente a Lei n. 10.973/2004, a ETEC tornou-se modalidade específica de contratação, com previsão no §2º-A do art. 19, tendo sido regulamentada pelo Decreto $\mathrm{n}^{\circ}$ 9.283/2018.

ETEC é uma forma de contratação inspirada em experiências internacionais de sucesso nos EUA e no Reino Unido. Ela deve estar envolvida em situação de incerteza, em que a solução do problema envolva risco para o Estado que, sozinho, não tem capacidade técnica de enfrentamento. Diante do quadro de incerteza, o Estado identifica potenciais interessados que apresentem chance de sucesso para contratação (podendo contratar múltiplas empresas privadas).

O modelo ETEC se enquadra perfeitamente ao caso de enfrentamento da Covid-19, ante as incertezas e riscos tecnológicos trazidos pelas vacinas que vêm sendo desenvolvidas a toque de caixa.

$\mathrm{Na}$ ETEC há um compartilhamento de riscos entre o Estado e o parceiro privado. $\mathrm{O}$ Tribunal de Contas de União publicou, em 2020, cartilhas para utilização das ETECs (TCU, 2020).

De acordo com referida cartilha (TCU, 2020), o procedimento de contratação da ETEC passa por três fases: planejamento da contratação, seleção do(s) fornecedor(es) e gestão do contrato.

O planejamento da contratação envolve cinco subetapas: estudos preliminares, mapa de riscos, comitê de especialistas, manifestação de interesse e termo de referência.

Nos estudos preliminares é possível obter uma estimativa preliminar do orçamento que será disponibilizado para a contratação por ETEC, embora não caiba fazer estimativas quanto aos custos do projeto.

Em relação ao mapa de riscos, importante ressaltar que o modelo adotado para elaboração do mapa deverá ser customizado segundo as especificidades do contratante ou inerentes ao processo de ETEC. O TCU recomenda seja feito o registro da análise realizada em documento específico.

O comitê de especialistas abre espaço à ponderação de pessoas externas ao processo.

A manifestação de interesse é recomendável para ouvir o mercado e subsidiar o contratante na estruturação da ETEC. 
Por fim, o termo de referência deve descrever o problema e as necessidades a ele relacionadas, de modo a permitir aos interessados compreender a demanda e apresentar projeto de P\&D para produto, serviço ou processo inovador que caracterize a possível solução, dispensada as especificações técnicas do objeto devido à complexidade da atividade de pesquisa, desenvolvimento e inovação ou por envolver soluções não disponíveis no mercado.

A segunda etapa compreende duas subetapas: negociação e termo de ratificação da dispensa de licitação (contratação).

A negociação deve envolver uma equipe do contratante, com integrantes de diferentes perfis: gestor, técnicos que assumem papeis variados no processo de negociação.

Já, na subetapa do termo de ratificação da dispensa de licitação (contratação) é importante prever no contrato sanções para o contratado, sobretudo no caso de situações de possíveis irregularidades, tomando-se o cuidado para não puni-lo em decorrência do risco inerente de insucesso. $\mathrm{O}(\mathrm{s})$ contrato(s) pode(m) ser celebrado(s) diretamente com ICT, entidades de direito privado sem fins lucrativos ou empresas, isoladamente ou em consórcios. Importante frisar que há possibilidade de haver mais de um contrato administrativo para o mesmo objeto no caso de ETEC.

Por fim, a terceira etapa prevê duas subetapas: acompanhamento e fiscalização do(s) contrato(s) e finalização do(s) contrato(s).

A subetapa do acompanhamento e fiscalização do(s) contrato(s) prevê a necessidade de o contratante ser informado pelo contratado acerca da evolução do projeto e seus resultados parciais. Caberá ao contratante monitorar a execução do contrato, mensurando os resultados alcançados em comparação com os previstos para avaliar as perspectivas de êxito ou indicar ajustes necessários.

A última subetapa diz respeito à finalização do(s) contrato(s), que poderá ocorrer por meio da entrega da solução final ou pela comprovação da impossibilidade de chegar a essa solução, mediante entrega parcial e evidências do avanço no desenvolvimento tecnológico realizado pelo(s) contratado(s).

O modelo de contratação a ser adotado pelo Estado depende de maiores detalhes da contratação como, por exemplo, da análise quanto à necessidade de condução de pesquisa, desenvolvimento e inovação em âmbito nacional ou se o objetivo é o mero fornecimento do produto já desenvolvido. 
A vacina em desenvolvimento pela Pfizer-BioNTech está em testes clínicos no Brasil desde julho de 2020 e, em 23/02/2021, obteve autorização de registro definitivo junto à Agência Nacional de Vigilância Sanitária (Anvisa).

O governo federal assinou em 19/03/2021 contrato para a aquisição de 100 milhões de doses da vacina contra covid-19 da Pfizer-BioNTech.

Caso o governo federal brasileiro consiga negociar a transferência de tecnologia, tudo leva a crer que o regime de contratação será por meio de ETEC.

\section{Conclusão}

A ciência, tecnologia e inovação, atualmente, condicionam a organização social e as formas existentes e emergentes de desigualdade e de exclusão tanto em cada sociedade como entre sociedades e regiões do mundo.

Líderes verdadeiramente comprometidos com o bem-estar geral da população têm a missão de valorizar a ciência e fazê-la permear seus cidadãos. Com a pandemia de COVID-19 restou demonstrado que, talvez, essa seja e a melhor forma de protegê-los.

As interações universidade-indústria-governo, que formam uma "hélice tríplice" de inovação e empreendedorismo, são a chave para o crescimento econômico e o desenvolvimento social baseados no conhecimento. (HENRY ETZKOWITZ, CHUNYAN ZHOU, 2017)

A tecnologia está presente em todos os setores da vida. Por isso, torna-se necessário que cientistas e as instituições de CT\&I dialoguem com a sociedade e, sobretudo, com os governos. É essa junção de interesses e investimentos que torna capaz a redução dos danos provocados por uma pandemia e, ao mesmo tempo, traz esperança em relação ao futuro da humanidade

Em relação à vacina para COVID-19 objeto do presente estudo, importa salientar que os dados aqui apresentados se reportam até a data de 19 de março de 2021, e que podem sofrer modificações.

Ante os estudos existentes até o momento, há bons indicativos de que ela terá sucesso nas etapas seguintes. 
Resta aos Estados, sobretudo ao Brasil, repensar a política (ou a falta dela) de investimentos em CT\&I, de modo que as próximas crises sejam enfrentadas com maior rapidez e eficiência.

\section{Referências bibliográficas:}

AGÊNCIA NACIONAL DE VIGILÂNCIA SANITÁRIA - ANVISA. Disponível em: https://www.gov.br/anvisa/pt-br/assuntos/noticias-anvisa/2020/covid-19-novo-modo-desubmissao-para-analise-de-vacina. Acesso em 12 nov. 2020.

AGÊNCIA NACIONAL DE VIGILÂNCIA SANITÁRIA - ANVISA. Disponível em: https://www.gov.br/anvisa/pt-br/assuntos/noticias-anvisa/2020/covid-19-novo-modo-desubmissao-para-analise-de-vacina/orientacoes-para-submissao-de-documentacao-de-vacinaspara-covid-19.pdf. Acesso em: 12 nov. 2020.

AGÊNCIA NACIONAL DE VIGILÂNCIA SANITÁRIA - ANVISA. Disponível em: https://www.gov.br/anvisa/pt-br/assuntos/noticias-anvisa/2020/nota-vacina-pfizer. Acesso em: 12 nov. 2020.

BBC NEWS BRASIL. Vacina da Pfizer: como funciona a nova tecnologia que pode revolucionar a imunização. 2020. Disponível em: https://www.bbc.com/portuguese/geral54881767. Acesso em: 12 nov. 2020.

BRASIL. Agência Nacional de Vigilância Sanitária - Anvisa. Vacina Contra Covid-19: dos testes iniciais ao registro. 2020. Disponível em: https://www.gov.br/anvisa/ptbr/assuntos/noticias-anvisa/2020/vacina-contra-covid-19-dos-testes-iniciais-ao-registro.

Acesso em: 12 nov. 2020.

BRASIL. Ministério da Saúde. Resposta nacional e internacional de enfrentamento ao novo coronavírus: linha do tempo. 2020. Disponível em: https://coronavirus.saude.gov.br/linha-do-tempo. Acesso em: 10 nov. 2020.

BIONTECH. Covid-19. 2020. Disponível em: https://biontech.de/covid-19. Acesso em: 06 nov. 2020.

CEPIC, Centro Paulista de Investigação Clínica - Pesquisa Clínica: Covid 19. 2020. Disponível em: https://www.cepic.com.br/pesquisa-clinica-covid-19. Acesso em: 11 nov. 2020.

ETZKOWITZ, Henry e Chunyan Zhou. Hélice Tríplice: inovação e empreendedorismo universidade-indústria-governo. Disponível em: https://www.scielo.br/scielo.php?script=sci_arttext\&pid=S0103-40142017000200023. Acesso em: 12 nov. 2020. 
EUA. Escritório da Opas e da Oms no Brasil. Organização Pan-Americana da Saúde. Covid19. 2020. Disponível em: https://www.paho.org/pt/covid19. Acesso em: 10 nov. 2020.

FOSUN PHARMACEUTICAL. Helps the World Fight Coronavirus with Global Resources: undeterred by hardships, helping friends from far and wide: fosun helps the world fight coronavirus with global resources. Undeterred by Hardships, Helping Friends from Far and Wide: Fosun Helps the World Fight Coronavirus with Global Resources. 2020. Disponível em: https://www.fosun.com/language/en/p/42015.html. Acesso em: 09 nov. 2020.

FURTADO, João. O estado da inovação o Brasil: evolução recente e perspectivas. In: Seminário Globalização e estratégias corporativas no século XXI - o desafio inovador brasileiro.O Estado da inovação no Brasil. 2005.Draft, 2005.

GADELHA, C. A. G.; AZEVEDO, N. Inovação em Vacinas no Brasil: Experiência Recente e Constrangimentos Estruturais, Hist. ciênc. saúde-Manguinhos, v. 10, n. supl.2, 2003.

GARCIA, Rafael. Pfizer oferece vacina a governo brasileiro por valor menor que o pago pelos EUA por dose. 2020. Disponível em: https://oglobo.globo.com/sociedade/coronavirus/pfizer-oferece-vacina-governo-brasileiropor-valor-menor-que-pago-pelos-eua-por-dose-1-24742888. Acesso em: 12 nov. 2020.

GRYZINSKI, Vilma. Vacina dos ricos e vacina dos pobres: diferença enorme de preço. 2020. Disponível em: https://veja.abril.com.br/blog/mundialista/vacina-dos-ricos-e-vacinados-pobres-diferenca-enorme-de-preco/. Acesso em: 12 nov. 2020.

HERPER, Matthew. Covid-19 vaccine from Pfizer and BioNTech is strongly effective, early data from large trial indicate. 2020. Disponível em: https://www.statnews.com/2020/11/09/covid-19-vaccine-from-pfizer-and-biontech-isstrongly-effective-early-data-from-large-trial-indicate/. Acesso em: 09 nov. 2020.

HOMMA, A.; MOREIRA, M. "Novos desafios para capacitação tecnologia nacional de vacinas: Inovação Tecnológica Autóctone e Transferência de Tecnologia", Cad. Saúde Pública, v, 24, n. 2. Rio de Janeiro, 2008.

IMPRENSA NACIONAL. Disponível em: https:/www.in.gov.br/web/dou/-/resolucao-re-n2.556-de-21-de-julho-de-2020-267802288. Acesso em: 11 nov. 2020.

LANGRETH, Robert; KRESGE, Naomi; GRIFFIN, Riley. Pfizer Soars as Vaccine Prevents 90\% of Covid Cases in Study. 2020. Disponível em: https://www.bloomberg.com/news/articles/2020-11-09/pfizer-s-covid-vaccine-prevents-90-ofinfections-in-large-study. Acesso em: 12 nov. 2020.

MANCINI, Donato Paolo; MILLER, Joe; KUCHLER, Hannah. Pfizer fecha venda de até 300 milhões de doses de vacina contra covid à UE. 2020. Disponível em: https://valor.globo.com/empresas/noticia/2020/11/12/pfizer-fecha-venda-de-ate-300-milhoesde-doses-de-vacina-contra-covid-a-ue.ghtml. Acesso em: 12 nov. 2020. 
PFIZER BRASIL. Sobre a Pfizer: institucional. 2020, A. Disponível em: https://www.pfizer.com.br/sobre-a-pfizer/institucional. Acesso em: 10 nov. 2020

PFIZER BRASIL; PFIZER FOUNDATION. Pfizer soma R\$ 2,5 milhões em doações para iniciativas voltadas ao combate do novo coronavírus no Brasil. 2020, B. Disponível em: https://www.pfizer.com.br/noticias/releases/pfizer-soma-25-milhoes-em-doacoes-parainiciativas-de-combate-ao-novo-coronavirus. Acesso em: 10 nov. 2020.

OLIVEIRA, Isaac de. Quem é a BioNTech, parceira da Pfizer na vacina para covid-19. 2020. Disponível em: https://einvestidor.estadao.com.br/negocios/quem-e-biontech-parceirapfizer-vacina-covid19. Acesso em: 09 nov. 2020.

PORTES, João Vitor de Araujo. O processo de transferência internacional de tecnologia no setor de imunobiológicos: um estudo de caso. Dissertação de mestrado Instituto Alberto Luiz Coimbra de Pós-Graduação e Pesquisa em Engenharia. UFRJ, 2012.

RAUEN, André Tortato. Vacina para o novo coronavírus: um caso clássico de encomenda tecnológico. IPEA, Nota técnica $\mathrm{n}^{\circ} 71$, jul.2020. Disponível em: https://www.ipea.gov.br/cts/images/central-

deconteudo/publicacoes/2020/.NT_Diset_N_71.pdf. Acesso em 10 nov. 2020.

RAUEN, André Tortato; BARBOSA, Caio Márcio Melo. Encomendas tecnológicas no Brasil: guia geral de boas práticas. Brasília: Ipea, 2019. Disponível em: https://www.ipea.gov.br/portal/images/stories/PDFs/livros/livros/190116_encomendas_tecnol ogicas.pdf. Acesso em 11 de novembro 2020.

SENADO FEDERAL. Disponível em: https://www12.senado.leg.br/noticias/materias/2015/02/26/promulgada-emenda-queincentiva-ciencia-tecnologia-e-inovacao. Acesso em 12 nov. 2020.

TRIBUNAL DE CONTAS DA UNIÃO - TCU. Disponível em: https://portal.tcu.gov.br/data/files/21/04/56/AE/5200371055EB6E27E18818A8/ETEC_projet o_contratacao_inovacao_administracao_publica.pdf. Acesso em: 10 nov. 2020.

UNIÃO EUROPEIA. Comissão Européia. Resposta ao coronavírus. Disponível em: https://ec.europa.eu/info/live-work-travel-eu/health/coronavirus-response/emergency-supportinstrument_pt. Acesso em: 10/11/2020.

VIDALE, Giulia. Governo federal ignora proposta de compra de vacina da Pfizer. 2020. Disponível em: https://veja.abril.com.br/saude/governo-federal-ignora-proposta-de-comprade-vacina-da-pfizer/. Acesso em: 09 nov. 2020. 